\title{
Amphiphilic Allylic Alkylation with Allyl Alcohols Promoted by Pd-Catalyst and Triethylborane
}

\author{
Masanari Kimura* and Yoshinao Tamaru \\ Department of Applied Chemistry, Faculty of Engineering, Nagasaki University \\ 1-14 Bunkyo, Nagasaki 852-8521, Japan \\ masanari@nagasaki-u.ac.jp
}

\begin{abstract}
The combination of Pd catalyst and triethylborane induces allylic alcohols to undergo direct electrophilic allylation of soft nucleophiles. Similar conditions also accelerate nucleophilic allylations of aldehydes and aldimines to provide homoallyl alcohols and homoallylamines, respectively. Moreover, 2-methylenepropane-1,3-diol undergoes a sequential amphiphilic activation to react with aldehydes and aldimines, giving rise to 3-methylenecyclopentanols and 3-methylenepyrrolidines.
\end{abstract}

Keywords: palladium, amphiphilic allylation, allyl alcohol, triethylborane, pyrrolidine 


\section{INTRODUCTION}

Allylation is among the most useful and efficient methods to construct complicated molecules in synthetic organic chemistry [1, 2]. This mini-review describes allyl alcohols that are capable of serving both as allyl cation and allyl anion equivalents and perform amphiphilic allylations under a catalytic system of palladium with triethylborane. Scheme 1 outlines the Pd-catalyzed activation of allyl alcohol in the presence of triethylborane. Triethylborane activates the allyl alcohol by coordination to the hydroxy group followed by oxidative addition of $\operatorname{Pd}(0)$ on the allylic $\mathrm{C}-\mathrm{O}$ bond to form a $\pi$-allylpalladium species. In this case, the $\pi$-allylpalladium species serves as an allyl cation if nucleophiles are present, regenerating an active $\operatorname{Pd}(0)$ species and triethylborane, and at the same time liberating one molecule each of the expected allylation product and water. In the absence of nucleophiles, triethylborane acts to promote an exchange reaction of the ethyl and allyl groups of the $\pi$-allylpalladium species, which gives rise to an allyl anion species along with decomposition of the ethylpalladium moiety into $\operatorname{Pd}(0)$, ethylene, and water. Thus, the combination of $\operatorname{Pd}(0)$ and triethylborane works for the generation of both allyl cation and allyl anion species directly from allylic alcohols to achieve amphiphilic allylic alkylations.

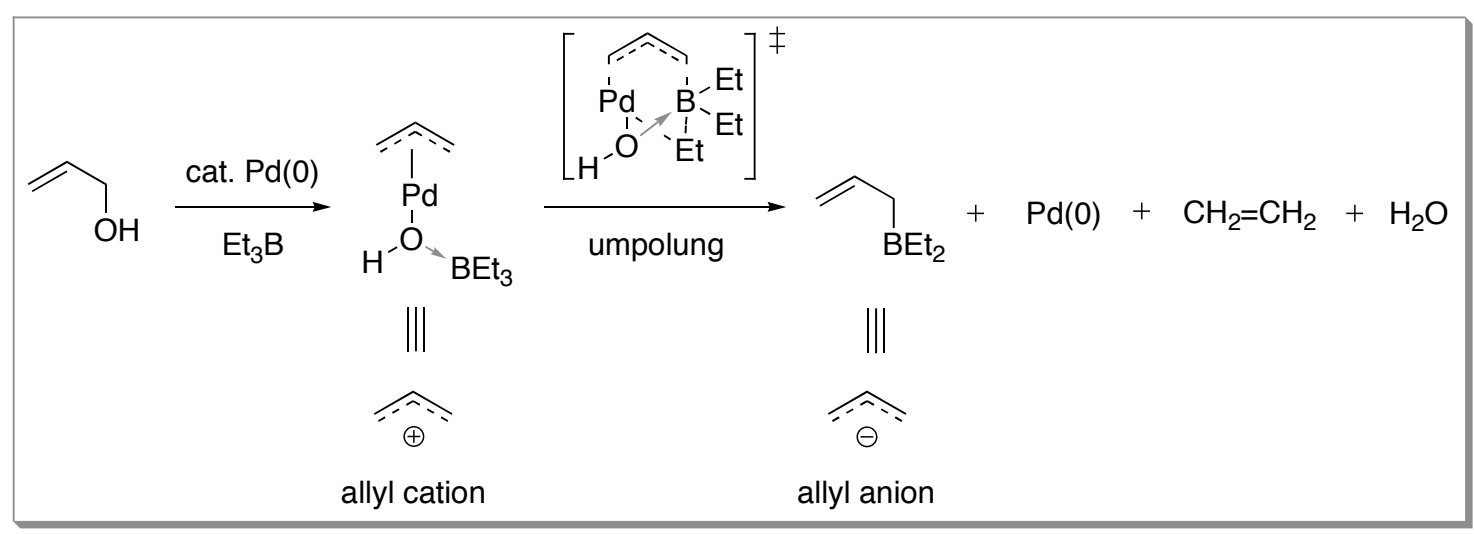

Scheme 1. Pd-Et ${ }_{3} B$ Promoted Formation of Allyl Cation and Allyl Anion from Allyl Alcohol

\section{ELECTROPHILIC ALLYLATION}

In the presence of a catalytic amount of $\mathrm{Pd}(\mathrm{OAc})_{2}$ and triethylborane, electrophilic allylation of amines with allylic alcohols takes place smoothly to provide $N$-allylated amines in excellent yields (Scheme 2) [3]. In this case, the choice of phosphine ligand is crucial to the successful performance of the reaction. For example, 
in the allylation of aliphatic amines, tri(n-butyl)phosphine is essential, whereas aromatic amines undergo the reaction with triphenylphosphine.

$C$-Allylation of active methylene compounds can be performed with similar ease. For example, $\alpha$-acetyl- $\gamma$-butyrolactone undergoes electrophilic allylation to give $\alpha$-allylated $\alpha$-acetyl- $\gamma$-butyrolactone in excellent yield at room temperature [4-6].

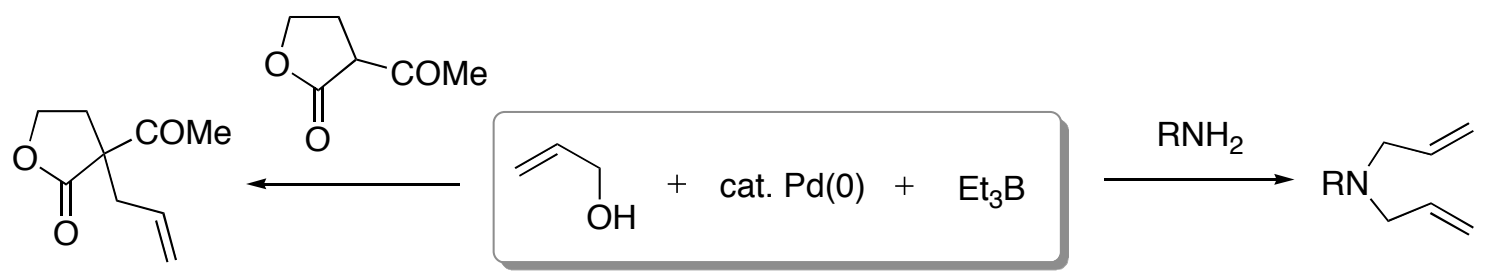

Scheme 2. Pd-Et 3 B Promoted Electrophilic Allylation of Soft Nucleophiles

Indole undergoes electrophilic allylation at the $\mathrm{C} 3$ position using one equivalent of allyl alcohol in the presence of a catalytic amount of $\mathrm{Pd}\left(\mathrm{PPh}_{3}\right)_{4}$ and triethylborane. Two equivalents of allyl alcohol provided C3 diallylated indolenine exclusively (Scheme 3) [7].

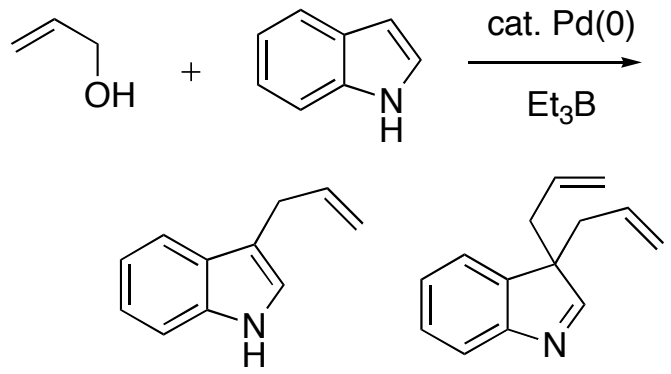

Scheme 3. Electrophilic Allylation of Indole

Under a similar catalytic system, electrophilic allylation of tryptophan methyl ester proceeds at the $\mathrm{C} 3$ position, giving anti diastereoselectivity with respect to the carbomethoxy group with concomitant amination at the $\mathrm{C} 2$ position, hence providing a pyrroloindole skeleton in excellent yield (Scheme 4). 

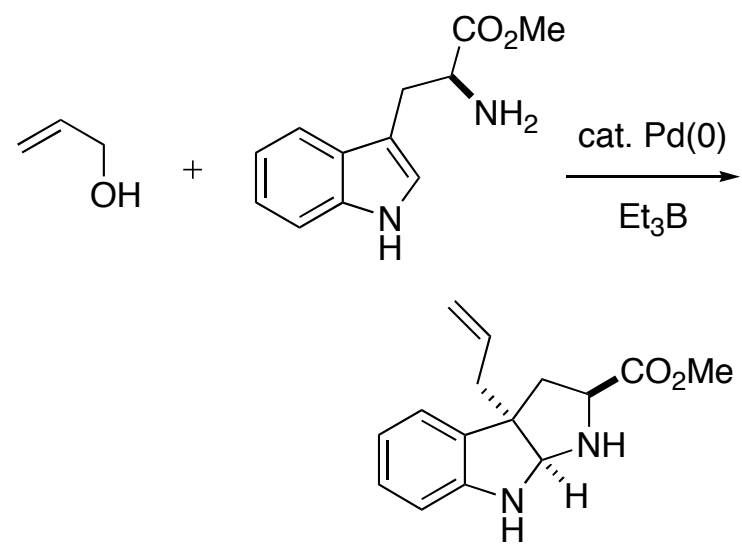

Scheme 4. Electrophilic Allylation of L-Tryptophan

The combination of triethylborane and $\mathrm{Pd}\left(\mathrm{PPh}_{3}\right)_{4}$ catalyst nicely promotes a wide variety of allylic alcohols to undergo either selective monoallylic alkylation of pyrroles at the $\mathrm{C} 2$ position with disubstituted allylic alcohols or diallylic alkylation at the $\mathrm{C} 2$ and $\mathrm{C} 5$ positions with monosubstituted allylic alcohols in good to excellent yields under neutral or weakly basic conditions (Scheme 5) [8]. It is possible to shift the selectivity in favor of monoallylation under conditions employing an excess amount of pyrrole and triethylamine as a promoter.

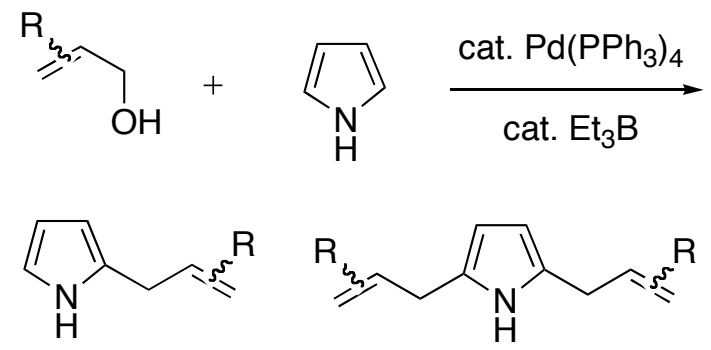

Scheme 5. Electrophilic Allylation of Pyrrole

The advantage of the present $\mathrm{Pd} / \mathrm{Et}_{3} \mathrm{~B}$ system is that it is also capable of direct Friedel-Crafts alkylation of naphthols and benzene polyols with allylic alcohols. This methodology is regarded as a C-H activation of aromatic compounds. 2-Naphthol underwent the allylic alkylation at the $\alpha$-position to provide 1-allyl-2-naphthol along with a 1,1-diallylated product (Scheme 6) [9]. 


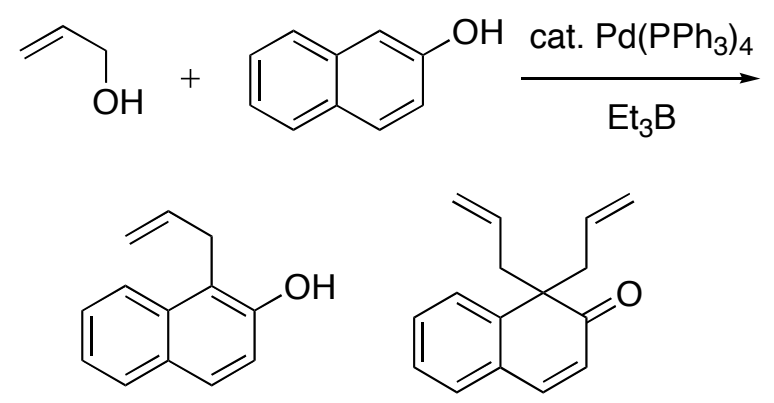

Scheme 6. Electrophilic Allylation of $\beta$-Naphthol

1,3,5-Trihydroxybenzene (phloroglucinol) is of great interest, not only because of the efficiency of the reaction that can be achieved in the presence of Pd catalyst, but also because of the unique structure of the product. The present $\mathrm{Pd} / \mathrm{Et}_{3} \mathrm{~B}$ system achieves exhaustive electrophilic allylation of 1,3,5-trihydroxybenzene to provide hexa-allylated cyclohexane-1,3,5-trione as the sole product (Scheme 7) [9]. This product with its high symmetry, six functionalized arms and distinctive conformational and electronic properties would be ideal as a core skeleton for supramolecular architectures having $\mathrm{C}_{3}$-symmetry [10].

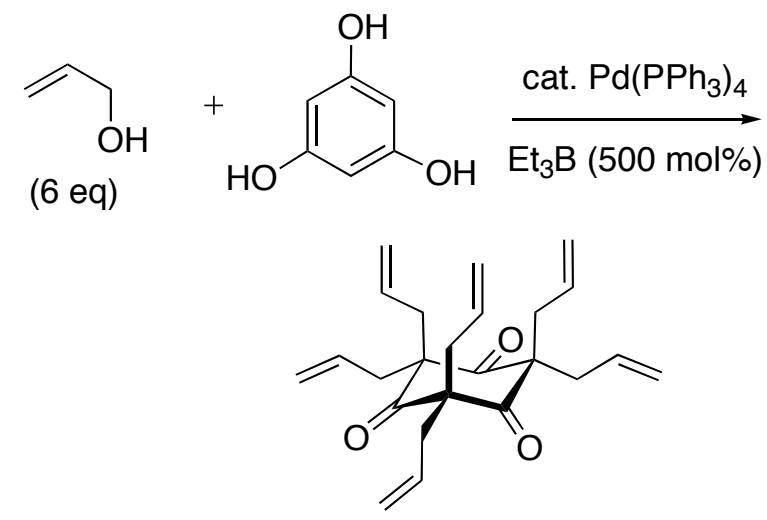

Scheme 7. Electrophilic Allylation of Trihydroxybenzene

The electrophilic allylation is applicable for selective cyclization in the synthesis of heterocyclic compounds (Scheme 8) [11]. The combination of $\operatorname{Pd}(0)$ catalyst and triethylborane at THF reflux promotes 5-exo trigonal cyclization of a 1:1 diastereoisomeric mixture of 3-hydroxy-2-(2-hydroxyethyl)-4-pentenamide to construct a tetrahydrofuran ring as a single isomer through nucleophilic attack of the hydroxy group on the $\pi$-allylpalladium species. 


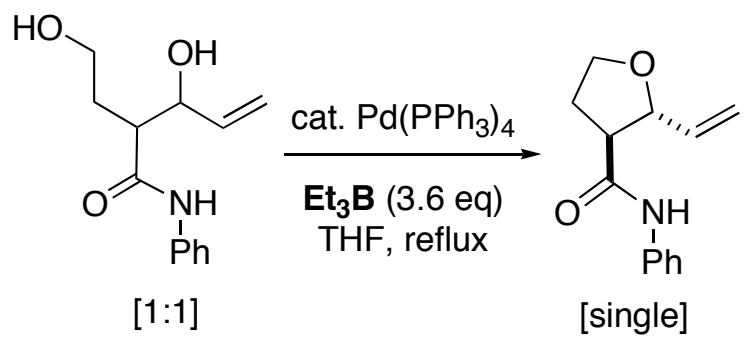

Scheme 8. Synthesis of Tetrahydrofuran Ring via $\mathrm{Pd} / \mathrm{Et}_{3} \mathrm{~B}$ Promoted Allylation

The $\alpha$-allylic alkylation of alkyl aldehydes and ketones with allylic alcohols reported so far requires both reaction partners to be preactivated: allylic alcohols as their esters and halides; and ketones and aldehydes as their metal enolates, enol silyl ethers, or enamines $[12,13]$. Under the $\mathrm{Pd} / \mathrm{Et}_{3} \mathrm{~B}$ reaction system, $\alpha$-allylation of alkyl aldehydes can be readily achieved by direct use of aldehydes and allylic alcohols. The secondary alkyl aldehyde cyclohexanecarbaldehyde nicely reacts with a wide structural variety of allylic alcohols to provide $\alpha$-allylated cyclohexanecarbaldehydes (Scheme 9) [14]. Primary alkyl aldehydes showed quite different reaction features (Scheme 10). 1 -Hexanal first underwent aldol condensation and provided a $\beta, \gamma$-unsaturated secondary alkylaldehyde, which then reacted as usual to provide the $\alpha$-allylated tertiary alkylaldehyde.

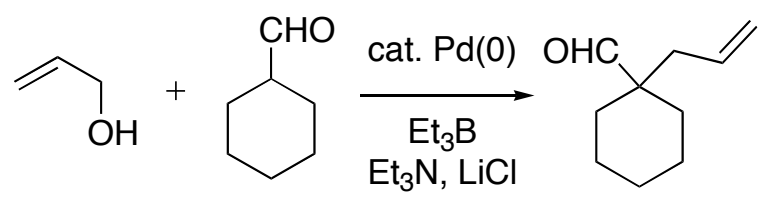

Scheme 9. Electrophilic $\alpha$-Allylation of sec-Alkylaldehyde
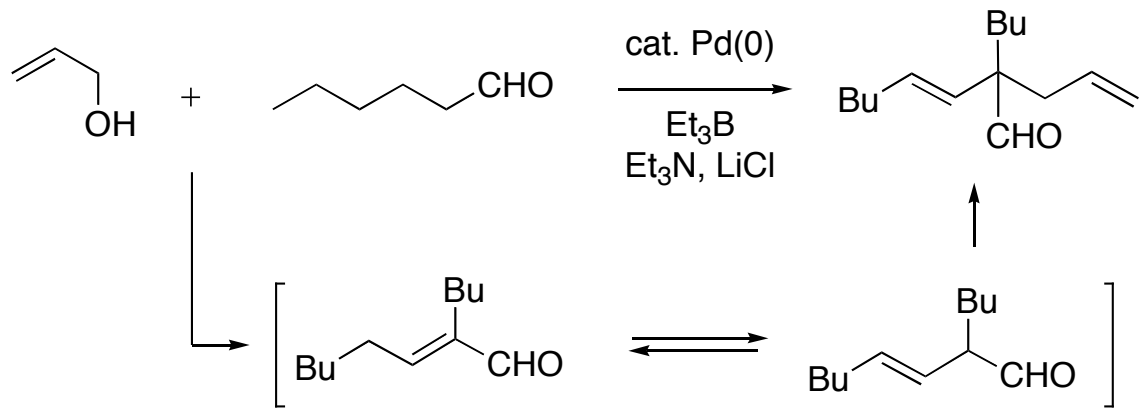

Scheme 10. $\alpha$-Allylation of Primary Alkylaldehyde with Allyl Alcohol 


\section{NUCLEOPHILIC ALLYLATION}

In the presence of nucleophiles and $\mathrm{Et}_{3} \mathrm{~B}$, the $\pi$-allylpalladium complex is converted to allylborane, which is known to serve as an allyl anion equivalent. The $\mathrm{Pd} / \mathrm{Et}_{3} \mathrm{~B}$ reaction system has been successfully extended to the nucleophilic allylation of various aldimines from aromatic aldehydes and even aliphatic aldehydes bearing enolizable protons. Aldimines prepared from isobutyraldehyde and $p$-anisidine $\left(\mathrm{PMPNH}_{2}\right)$ in situ by azeotropic removal of water were treated with allyl alcohol in the presence of $\mathrm{Pd}(\mathrm{OAc})_{2}, n-\mathrm{Bu}_{3} \mathrm{P}$, and $\mathrm{Et}_{3} \mathrm{~B}$ (Scheme 11) [15]. Lactols produced aldimines by exposure to $p$-anisidine and nicely underwent nucleophilic allylation in reasonable yields (Scheme 12) [16]. The reaction showed high regio- and stereoselectivity to provide the expected product as a single stereoisomer.

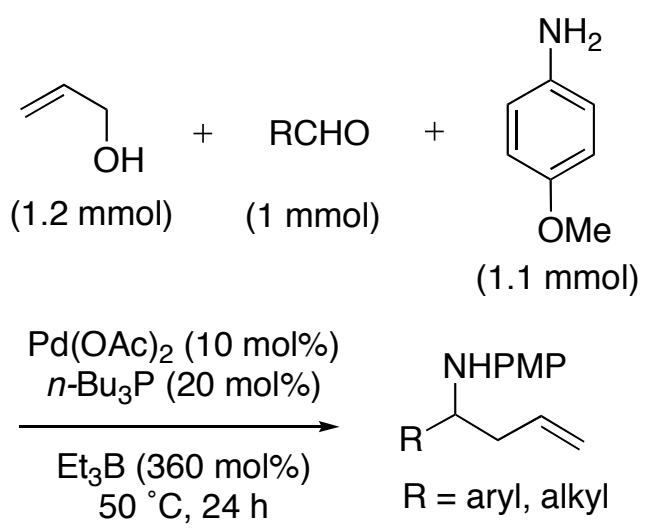

Scheme 11. Nucleophilic Allylation of Aldimine

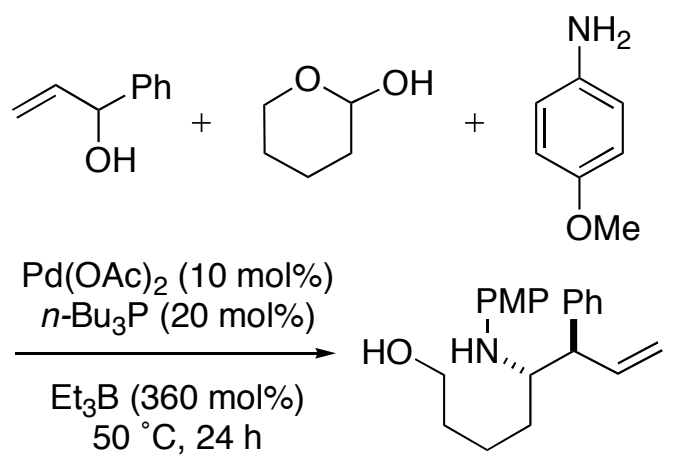

Scheme 12. Nucleophilic Allylation of N,O-Acetal 
The reaction can also be extended to the nucleophilic allylation of ribose. This route may be synthetically useful because the reaction can be performed without protection of the polyhydroxy functional groups (Scheme 13) [16].

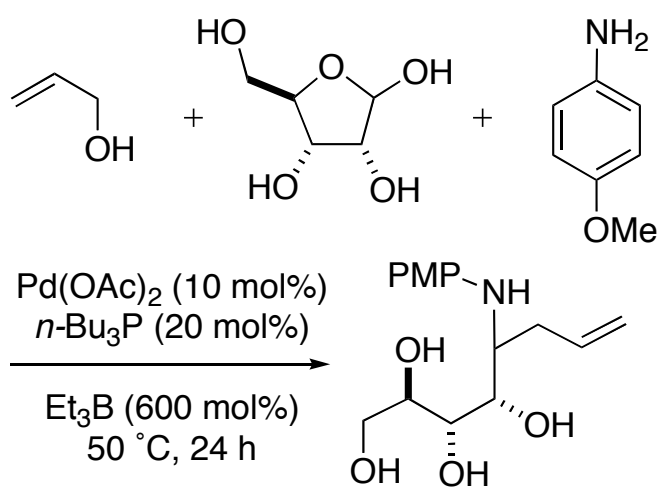

Scheme 13. Nucleophilic Allylation of D-Ribose Analogue

\section{AMPHIPHILIC ALLYLATION}

A straightforward and convenient method for amphiphilic allylation of sec-alkyl aldehydes with commercially available 2-methylenepropane-1,3-diol through a trimethylenemethane equivalent was established with the $\mathrm{Pd}$ catalyst/ $\mathrm{Et}_{3} \mathrm{~B}$ system. In the presence of triethylamine and $\mathrm{LiCl}$, one of the allylic alcohol moieties of the symmetrical bis-allyl alcohol serves as an allyl cation equivalent and reacts with cyclohexanecarbaldehyde to provide the $\alpha$-allylated hemiacetal in high yield (Scheme 14) [17]. In the absence of these additives, the remaining allylic alcohol moiety undergoes nucleophilic allylation on the aldehyde carbonyl carbon to provide 3-methylenecyclopentanol in good yield.

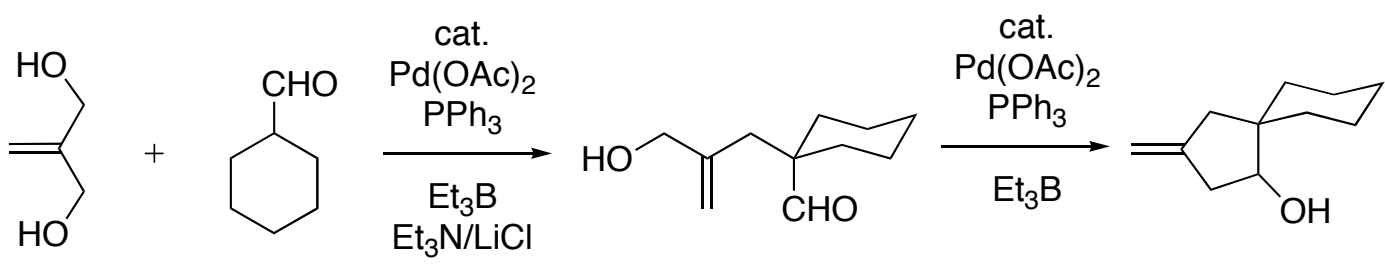

Scheme 14. Amphiphilic Allylation of Aliphatic Aldehyde with 2-Methylene-1,3-propanediol 
With the more acidic $\alpha$-hydrogen of sec-alkyl aldehydes, electrophilic and nucleophilic allylations proceed in one-pot. For example, $\alpha$-phenylpropionaldehyde reacted with 2-methylenepropane-1,3-diol in the presence of Pd catalyst and $\mathrm{Et}_{3} \mathrm{~B}$ to provide the desired product in one-pot (Scheme 15).

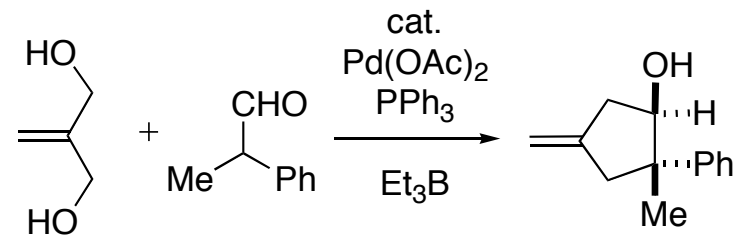

Scheme 15. One-pot Synthesis of 3-Methylenecyclopentanol

A similar catalytic system consisting of a $\mathrm{Pd}$ catalyst and $\mathrm{Et}_{3} \mathrm{~B}$ promotes amphiphilic allylation of aldimines, which are prepared from a wide variety of amines and aldehydes, with 2-methylenepropane-1,3-diol to give pyrrolidines. Notably, the order of sequential amphiphilic allylation of aldimines is apparently opposite to that of aldehydes (Schemes 16 and 17) [18].
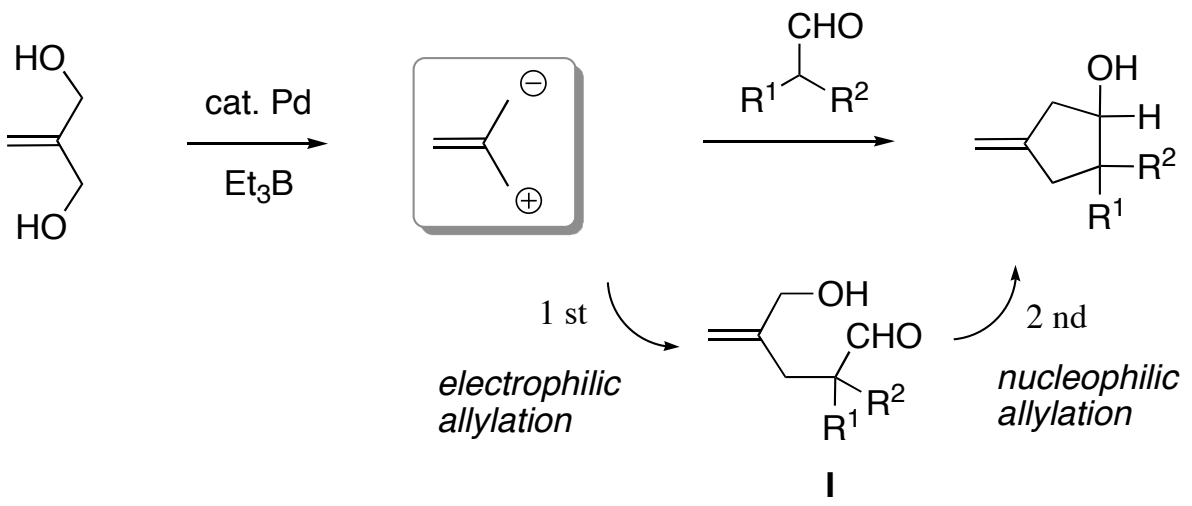

Scheme 16. Amphiphilic Allylation of Aldehydes with 2-Methylenepropane-1,3-diol

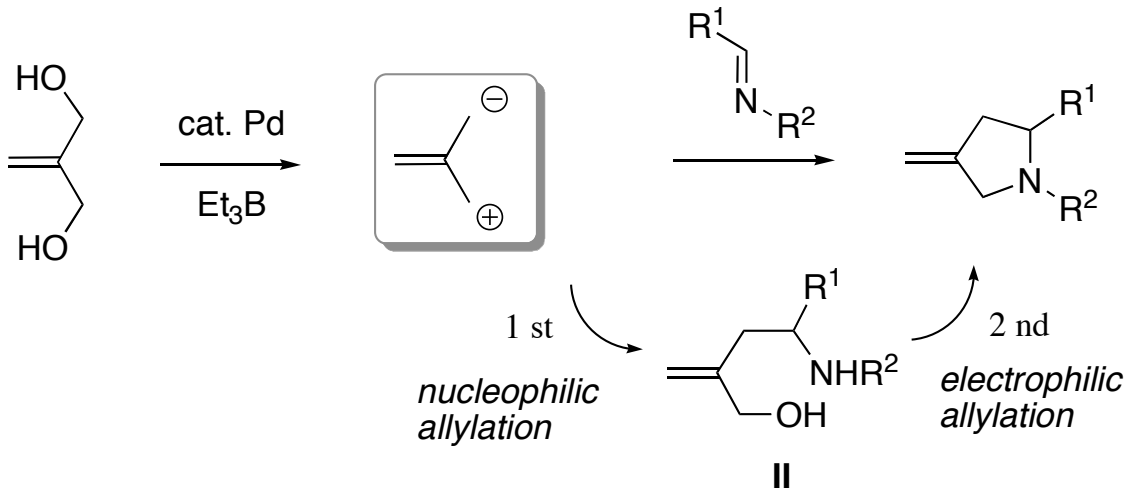

Scheme 17. Amphiphilic Allylation of Aldimines with 2-Methylenepropane-1,3-diol 
In the presence of $\mathrm{Pd}$ catalyst and $\mathrm{Et}_{3} \mathrm{~B}$, aldimines generated from aromatic amines and aldehydes are suitable electrophiles for amphiphilic allylation. The reaction was successful for aromatic amines and aldehydes with either electron-donating or electron-withdrawing groups to provide pyrrolidines in reasonable yields (Scheme 18).

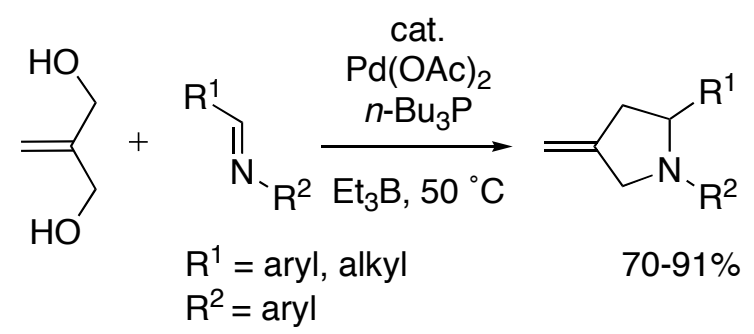

Scheme 18. $\mathrm{Pd} / \mathrm{Et}_{3} \mathrm{~B}$ Promoted Amphiphilic Allylation

However, the combination of aliphatic amines and aliphatic aldehydes produced a complex mixture. Therefore, an alternative reaction route using a Pd catalyst and $\mathrm{Et}_{2} \mathrm{Zn}$ was developed for the amphiphilic allylation of aldimines. This was composed of an aliphatic aldehyde and an aliphatic amine with 2-methylenepropane-1,3-dibenzyl ether (Scheme 19). The reaction proceeds smoothly at room temperature and the desired products were obtained in excellent yields. Thus, by employing either $\mathrm{Et}_{3} \mathrm{~B}$ or $\mathrm{Et}_{2} \mathrm{Zn}$, the one-pot synthesis of pyrrolidines may be carried out with a wide variety of aromatic and aliphatic aldehydes and amines.

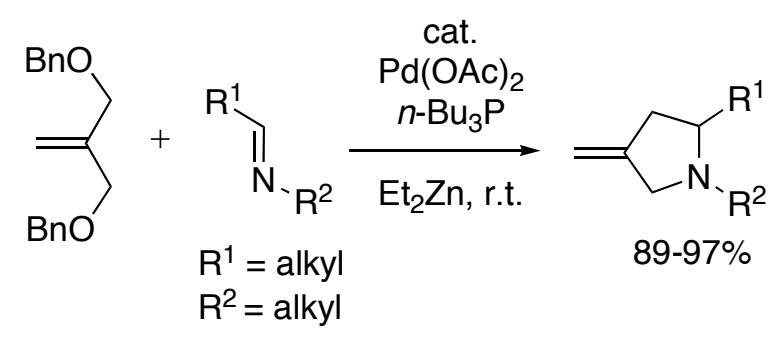

Scheme 19. $\mathrm{Pd} / \mathrm{Et}_{2} \mathrm{Zn}$ Promoted Amphiphilic Allylation

Unsymmetrically substituted bis-allyl alcohols and their dibenzyl ethers show very interesting regio- and stereoselectivities depending on whether $\mathrm{Et}_{3} \mathrm{~B}$ or $\mathrm{Et}_{2} \mathrm{Zn}$ is employed. 1-Phenyl substituted bis-allylic alcohol, upon treatment with $\mathrm{Et}_{3} \mathrm{~B}$, underwent nucleophilic allylation at the less substituted allylic position, followed by intramolecular electrophilic allylation at the less sterically hindered end of the allyl 
moiety (Scheme 20). In contrast, the $\mathrm{Pd} / \mathrm{Et}_{2} \mathrm{Zn}$ catalytic system promoted nucleophilic allylation of the dibenzyl ether at the less substituted position, and subsequent electrophilic allylation proceeded at the $\mathrm{Ph}$-substituted allylic position to afford trans-2,5-diphenylpyrrolidine quantitatively. These regio- and stereoselectivities are in contrast to the result obtained by the Trost protocol which causes cycloaddition with substituted TMM precursors generated from unsymmetrical 2-[(trimethylsilyl)methyl]allyl acetate by using a Pd catalyst (Scheme 21) [19].

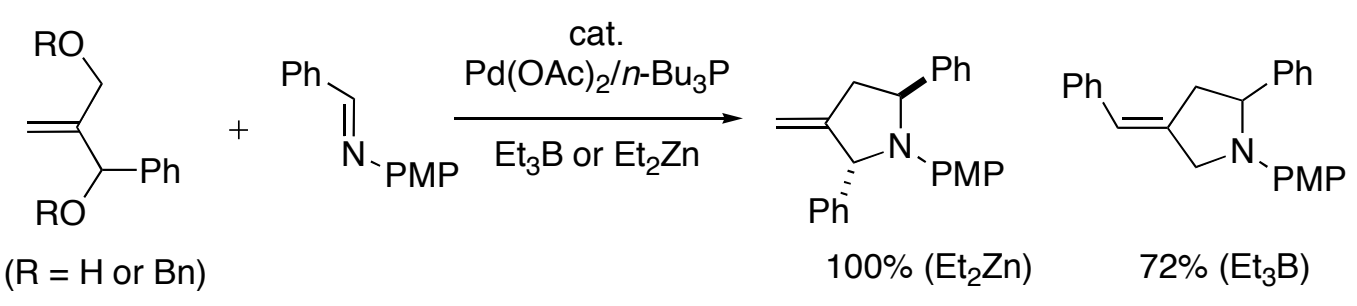

Scheme 20. Allylation of Aldimine with Unsymmetrically Substituted Bis-allylic Alcohols

$\mathrm{Ph}$<smiles>C=C1CC(c2ccccc2)N([Pb])[C@@H]1c1ccccc1</smiles>

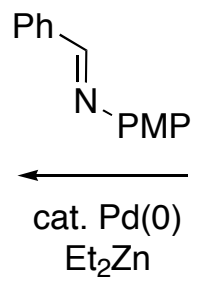<smiles>C=C(CS(C)(=O)=O)C(OC(C)=O)c1ccccc1</smiles>

TMS = trimethylsily $\mid$

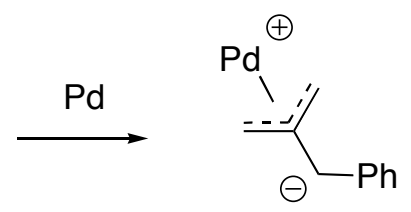<smiles>C=C(CO)C(O)C(O)c1ccccc1</smiles>

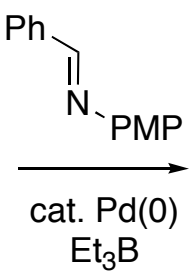<smiles>O=PN1C/C(=C/c2ccccc2)CC1c1ccccc1</smiles>
(Our method)<smiles>C(=NC=Nc1ccccc1)c1ccccc1</smiles><smiles>C=C1CN([Pb])C(c2ccccc2)C1c1ccccc1</smiles>
(Trost method)

Scheme 21. Selective Synthesis of Conceivable Substituted Pyrrolidines

The single stereoisomer obtained with the $\mathrm{Pd} / \mathrm{Et}_{2} \mathrm{Zn}$ catalytic system was successfully converted into an internal olefin with $E$-stereoselectivity using a $\mathrm{Pd} / \mathrm{Et}_{3} \mathrm{~B}$ catalyst at $50{ }^{\circ} \mathrm{C}$ for $72 \mathrm{~h}$. Interestingly, under similar conditions, trans-2-methyl-5-phenylpyrrolidine isomerized to a diastereomeric mixture of transand cis isomers in a 1:1 ratio (Scheme 22). These results suggest that intramolecular 
electrophilic allylation in the presence of $\mathrm{Pd} / \mathrm{Et}_{3} \mathrm{~B}$ is a reversible process. The application and extension of this method for the asymmetric synthesis of physiologically active molecules with pyrrolidine frameworks are currently being investigated.

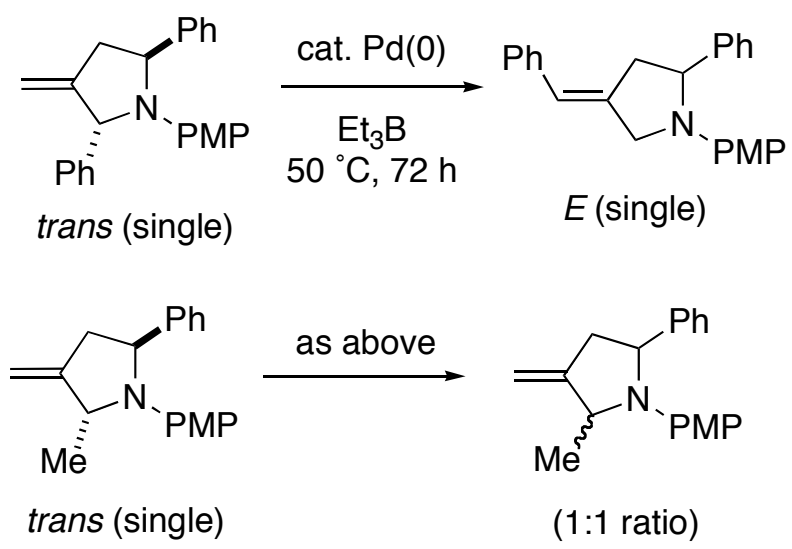

Scheme 22. Different Reactivity of Alkyl- and Aryl-substituted Pyrrolidines

\section{CONCLUSION}

The $\mathrm{Pd} / \mathrm{Et}_{3} \mathrm{~B}$ catalytic system promotes the generation of allyl cations, allyl anions, and zwitterionic trimethylenemethane species from the corresponding allylic alcohols. Allyl cation species react with a wide variety of nucleophiles, e.g., amines, active methylene compounds, aromatic compounds, and at the $\alpha$-position of alkyl aldehydes. Allyl anion species react with aldehydes and aldimines to give homoallyl alcohols and homoallylamines. Zwitterionic trimethylenemethane species, generated from 2-methylenepropane-1,3-diol, undergo a sequential amphiphilic activation to react with aldehydes and aldimines to give rise to 3-methylenecyclopentanols and 3-methylenepyrrolidines, respectively.

\section{ACKNOWLEDGEMENTS}

Financial support from the Ministry of Education, Culture, Sports, Science, and Technology, Japan is gratefully acknowledged. 


\section{REFERENCES}

[1] Tamaru, Y. Eur. J. Org. Chem. 2005, 13, 2647-2656.

[2] Tamaru, Y. J. Organomet. Chem. 1999, 576, 215-231.

[3] Kimura, M.; Futamata, M.; Shibata, K.; Tamaru, Y. Chem. Commun. 2003, 234-235.

[4] Kimura, M.; Mukai, R.; Tanigawa, N.; Tanaka, S.; Tamaru, Y. Tetrahedron 2003, 59, 7767-7777.

[5] Horino, Y.; Naito, M.; Kimura, M.; Tanaka, S.; Tamaru, Y. Teatrahedron Lett. 2001, 42, 3113-3116.

[6] Tamaru, Y.; Horino, Y.; Araki, M.; Tanaka, S.; Kimura, M. Teatrahedron Lett. 2000, 41, 5705-5709.

[7] Kimura, M.; Futamata, M.; Mukai, R.; Tamaru, Y. J. Am. Chem. Soc. 2005, 127, 4592-4593.

[8] Kimura, M.; Fukasaka, M.; Tamaru, Y. Heterocycles 2006, 67, 535-542.

[9] Kimura, M.; Fukasaka, M.; Tamaru, Y. Synthesis 2006, 3611-3616.

[10] Li, H.; Homan, A. H.; Lampkins, A. J.; Ghiviriga, I.; Castellano, R. K. Org. Lett. 2005, 7, 443-446.

[11] Kimura, M.; Toyoda, K.; Kohno, T. manuscript under preparation.

[12] Tsuji, J.; Minami, I.; Shimizu, I. Chem. Lett. 1983, 1325-1326.

[13] Trost, B. M.; Keinan, E. Tetrahedron Lett. 1980, 21, 2591-2594.

[14] Kimura, M.; Horino, Y.; Mukai, R.; Tanaka, S.; Tamaru, Y. J. Am. Chem. Soc. 2001, 123, 10401-10402.

[15] Shimizu, M.; Kimura, M.; Watanabe, T.; Tamaru, Y. Org. Lett. 2005, 7, 637-640.

[16] Kimura, M.; Hashimoto, M.; Tamaru, Y. manuscript under preparation.

[17] Mukai, R.; Horino, Y.; Tanaka, S.; Tamaru, Y.; Kimura, M. J. Am. Chem. Soc. 2004, 126, 11138-11139.

[18] Kimura, M.; Tamaki, T.; Nakata, M.; Tohyama, K.; Tamaru, Y. Angew. Chem. Int. Ed. 2008, 47, 5803-5805.

[19] Trost, B. M.; Marrs, C. M. J. Am. Chem. Soc. 1993, 115, 6636-6645. 